\title{
Establishing global climate resilience to persistent organic pollutants through the private sector: a call to reform institutional standards of the International Finance Corporation
}

Lok Ming Tam ${ }^{1,4}$, Wesley Chiang 2,4 , Khang T. Huynh ${ }^{3,4}$

1 University of Rochester, Department of Biology, Rochester, NY

${ }^{2}$ University of Rochester Medical Center, Department of Biochemistry and Biophysics, Rochester, NY

3University of Rochester, Department of Biomedical Engineering, Rochester, NY

4University of Rochester Science Policy Initiative

https://doi.org/10.38126/ISPG180210

Corresponding author: lokming.tam@rochester.edu

Keywords: climate change adaptation; persistent organic pollutants; environmental fate and transport; environmental toxicology; World Bank

Executive Summary: Persistent organic pollutants (POPs) are toxic synthetic chemicals prevalent in the environment that have been linked to serious health effects including various cancers, hypertension, and diabetes. Owing to their unique physicochemical properties, POP accumulation in the environment poses a serious risk to public health. Over the last few decades global climate change (GCC) has exacerbated increasing temperature and extreme weather events, which reduce the storage capacity of POPs in the environment and precipitate their global remobilization. If we remain unprepared to block GCC-associated release of POPs globally, our adaptation and resilience to climate change will be jeopardized. The Stockholm Convention, an international treaty that aims to reduce and eliminate POPs, is not fully enforceable due to a lack of environmental funds for governments of developing countries. One way to circumnavigate these financial hurdles is to create new markets for POP removal through the private sector. We recommend the International Finance Corporation, the private sector arm of the World Bank, reform its institutional regulations to consistently guarantee funding for proactive measures against POPs. We additionally recommend investing in local POP removal infrastructure projects that encourage economic growth.

\section{Introduction}

Persistent organic pollutants (POPs) have been extensively used for pesticides, malaria control, and industrial chemicals in the post-war era. The use of POPs resulted in unprecedented environmental proliferation before their eventual restrictions in the 1970s (Ashraf 2017). Nowadays, POPs are generated unintentionally from improper waste management, herbicides, and industrial processes (Committee on the Significance of International Transport of Air Pollutants 2010). They are resistant to degradation and prone to accumulation in the environment due to their high chemical stability, semi-volatile nature, and high fat solubility (Scheringer 2009; Eckley 2001; Wania and Mackay 1996). According to the World Health Organization, POPs result in 4.9 million deaths annually and millions more are affected by POP-associated debilitations or diseases (Milic et al. 2019; Prüss-Ustün et al. 2011); toxic effects on humans include diabetes, cancer, and disorders in various systems (i.e. cardiac, neurological, reproductive) (Milic et al. 2019; Varjani, Gnansounou, and Pandey 2017). The impacts on human health are endemic to the environmental 
impacts of POP toxicity due to accumulation through food supply chains; other effects include altered animal behavior and ecosystems due to toxicity or habitat disruption (Alharbi et al. 2018). Acknowledging the risks posed by POPs, the United Nations Environment Programme convened an international negotiating committee to adopt the Stockholm Convention in 2001. Signatories of the Stockholm Convention commit to implement restrictions on the production, use, and emission of POPs (Rigét et al. 2019).

Despite this global commitment, the persistent threat of climate change exacerbates human exposure to POPs (Kallenborn et al. 2012). Normally polar ice covers, oceans, forests, soils, sediments, and vegetation, even in remote places such as the Arctic (Rigét et al. 2019), constitute major natural reservoirs that trap POPs. Global temperature rise and increasingly volatile weather patterns melt ice caps and disrupt soils through flooding. These climate change events release POPs from reservoirs and accelerate its bioaccumulation in vegetation and food chains, eventually resulting in human consumption (Ma, Hung, and Macdonald 2016; Kallenborn et al. 2012). The toxicity of certain POPs is also known to increase with temperature (Noyes et al. 2009). Therefore, unabated climate change will very likely cause global remobilization of these POPs, ultimately compromising global health (Wang, Sun, and Yao 2016).

Increasing climate change adaptation and resilience can be achieved through multilateral efforts to eliminate and restrict POPs. Unfortunately, the issues of altered global environmental behaviors of POPs and its consequential potential public health concerns are often overlooked within the greater discussion of climate change. The Stockholm Convention does not stipulate robust enforcement mechanisms. Instead, governments formulate their own National Implementation Plans (NIPs) and are at liberty to implement them without stringent oversight. However, executing NIPs presents various challenges to developing countries that lack economic resources. Countries are sometimes granted exemptions when the use of certain POPs demonstrates public health benefits and economic restrictions prevent them from adopting POP-free alternatives. One prominent example is the use of DDT in temperate regions to kill mosquitoes, a vector for the deadly disease malaria. Here, preventing unnecessary deaths outweighs the eventual risk of detrimental health effects through bioaccumulation of DDT. In such situations, countries must prove that the long-term risks of POP exposure from these projects are less significant compared to the public health benefits and economic gain (Secretariat of the Stockholm Convention n.d.; Alharbi et al. 2018). Aside from grants dispersed by the Global Environmental Facility (GEF), few mechanisms exist to fund initiatives for POP removal or remediation (World Bank Group 2017). This is especially problematic for poorer nations that rely primarily on GEF funding that, amongst multiple projects, do not prioritize POP reduction. Additionally, the GEF does not have the capacity to assess whether funds allocated for POP removal are appropriately or effectively used (Ashton and Kohler 2010).

The mission to reduce POPs worldwide requires proactive efforts rather than voluntary commitments but should not punish countries that are unable to meet their NIP obligations. As the UN's private sector arm, the International Finance Corporation (IFC) is uniquely positioned to address both these problems by fostering partnerships with the private sector. The need for POP removal across the globe is an untapped market that the IFC can seed, potentially solving a widespread environmental problem while simultaneously creating jobs within local economies.

\section{Current IFC sustainability initiatives inadequately address the risk of POPs}

The ratification of the 1944 Bretton Woods agreements formalized an international system of monetary policies that eventually developed into the World Bank Group (WBG). Within the WBG is the IFC, which provides financial services and products to businesses seeking to invest in developing countries (The World Bank n.d.). Unlike other WBG organizations, the IFC often adopts a proactive strategy to stimulate local economies by promoting new markets. In line with the UN's Sustainable Development Goals, the IFC invests in climate-related industries as a leading financier of Green Bonds Program "climate-smart" projects and requires these projects to adhere to its Policy in Environmental and Social Sustainability (Morgado and Lasfargues 2017; International Finance Corporation 2012, n.d.). Despite investments in climate-related industries, 
structural barriers prevent the IFC from adequately addressing POP reduction.

For all clients, the IFC requires a plan to meet environmental standards and regulations as dictated by the host nation, IFC, and the World Bank (International Finance Corporation n.d., n.d.). Yet the ambiguity of these guidelines permits clients to engage in activities that release POPs to the environment (International Finance Corporation n.d.). For example, the Office of the Compliance Advisor/Ombudsman (CAO) (the main regulatory body of the IFC) and non-governmental organizations (NGOs), like Inclusive Development International, have substantiated numerous times the IFC's inability to adequately assess environmental risks and mitigation strategies from sub-clients funded through financial intermediaries (FIs). They suggest this is possibly attributed to lax reporting requirements (Office of the Compliance Advisor Ombudsman 2012, [a] 2017; Inclusive Development International 2016). This loophole, which allows sub-clients to evade compliance with the IFC's Sustainability Framework (Office of the Compliance Advisor Ombudsman 2019), has resulted in projects that enable proliferation of POPs without adequate mitigation and removal strategies. One example is high-efficiency coal-based power plants that release POPs as a byproduct of coal flue gas and coal ash (in addition to greenhouse gases) (Office of the Compliance Advisor Ombudsman 2017b, 2019; Meij and te Winkel 2007). Another is energy efficiency projects on fossil fuel power plants that reduce greenhouse gases, but still result in a net increase of waste products, including POPs (Center for International Climate Research 2015; Sahu et al. 2009).

Not only do the IFC's guidelines inadequately address the risk POPs pose to a climate resilient future, they also do not stipulate such activities as eligible investments for Green Bond-funded projects (International Finance Corporation n.d.). While the IFC identifies activities pursuing climate adaptation and resilience as pertinent to its climate-smart portfolio, these seem to be primarily focused on sustainable infrastructure, resource management, and emission reduction (International Finance Corporation 2020). Proactive infrastructure and solutions to mitigate the threat of releasing hazardous chemicals, including POPs from their environmental reservoirs, must not be ignored in efforts towards a climate resilient future.

\section{Recommendations}

To effectively leverage its role in steering private sector works towards sustainable development, the IFC needs to reevaluate how its guidelines and policies impact the activities it finances with respect to POP generation. Rather than implementing broad regulations on hazardous wastes to include POPs, it needs to set comprehensive standards and implementation strategies that proactively reduce the net release of POPs into the environment. This includes establishing goals and investment opportunities aimed at removing POPs already present in environmental reservoirs. These strategies will better align the outcomes of IFC funded activities with the UN's mission to establish economic and environmental sustainability in their host communities. Therefore, we ask that the Board of Directors of the IFC pass a resolution that commits the organization to the following recommendations.

\section{i. Prescribe clearer guidelines on the environmental risks of POPS.}

Under its various policies, frameworks, and standards, the IFC references enforcement of the Stockholm Convention's goals. As mentioned previously, the IFC lacks the ability to sufficiently monitor the activities of its sub-clients. To rectify this loophole, the IFC needs to introduce guidelines requiring all sub-clients provide documentation of clear environmental risk assessments and mitigation strategies that comply with the IFC Sustainability Framework. Such documentation would inherently include assessments regarding POPs.

These gaps in oversight can be further addressed through the IFC's Exclusion List which specifies activities it does not fund (Office of the Compliance Advisor Ombudsman 2012). Though many of these activities are examined for their contributions to unsustainable practices, secondary impacts for environmental hazards like POPs must also be considered. Specifically, the IFC needs to expand this list to include activities that risk secondary release of POPs from environmental reservoirs. Improving evaluation standards of sub-clients and banning activities that release POPs from environmental reservoirs will enable the IFC to effectively monitor 
and prevent any funded activities that increase POPs in the environment.

ii. Introduce language that allows Green Bond-funded projects to invest in POP removal technology.

IFC Green Bond-funded projects must adhere to the IFC's Performance Standards regarding sustainability. The introduction of the first recommendation would ensure such activities do not exacerbate the threat of POPs to climate resilience (International Finance Corporation n.d.). However, "climate-smart" projects funded through the IFC's Green Bond Program should do more than simply mitigate the risk of POP production; rather, the IFC should actively invest in projects that reduce the environmental levels of POPs.

Potential activities can serve to transition manufacturing and electricity generation away from practices that generate carcinogenic POPs (World Bank Group 2017). Other activities can seek to develop industrial centers specialized in removing POPs from known reservoirs. For example, one emerging technology for decomposing POPs in drinking and waste waters is photocatalysis, which uses light to split water into free radicals that degrade POPs. This technology is significantly cheaper and more efficient at removing POPs than conventional methods (Nguyen et al. 2020; Asha et al. 2015). Integrating photocatalytic technologies with current water treatment infrastructure in developing nations will increase job opportunities in an environmentally sustainable market. However, this approach cannot be realized without substantial private sector investment (Muller, Saari, and Novack 2010). The implementation of this recommendation will transition the IFC away from evaluating funding as a trade-off between potential public health risks and economic development. Rather, funded activities have the potential to uplift poorer communities through both improved health outcomes and new jobs.

iii. Engage local communities of sponsored projects as an accountability mechanism.

Another issue noted by CAO was the lack of proper grievance mechanisms and guidance to meet accountability measures available to the local communities of IFC-funded activities (Office of the Compliance Advisor Ombudsman 2017a). Many of these communities require the assistance of NGOs or advocacy groups to navigate how to voice their complaints to the CAO or other oversight groups. This partly arises from being unaware of not only their options, but also the health-related risks of their exposure to POPs (Bavuge, Kamatali, and Mbonigaba 2020). Therefore, IFC-funded projects must incorporate community engagement to communicate why transitioning from POPs benefits both the local economy and public health. These communities will be provided with information about the health impacts of POP emissions, but also understand what mechanisms exist to assist with keeping IFC-funded projects and sub-projects within compliance of IFC's environmental standards. To ensure the compliance to such stipulations, the IFC should provide sub-clients with expertise on making environmental risk assessments and training on effective engagement strategies with their local communities.

\section{Conclusions}

Persistent organic pollutants are a critical threat to public health and environmental sustainability that will be further exacerbated by ongoing climate change. Aggressive measures that drastically reduce POP production and removal from environmental reservoirs must be adopted. We view the private sector as the most economically viable approach to reducing the environmental risks of POPs through job creation from environmental infrastructure projects. Therefore, we call upon the Board of Directors of the IFC to pass a resolution to reform its institutional standards regarding POPs. Commitments to the Stockholm Convention must be uncompromising but fair, especially to developing countries; strengthening compliance and oversight must accompany funds dedicated to POP regulation and removal in the private sector. These concrete actions must be implemented immediately to safeguard public health against these harmful POPs. 


\section{References}

Alharbi, Omar M. L., Al Arsh Basheer, Rafat A. Khattab, and Imran Ali. 2018. "Health and Environmental Effects of Persistent Organic Pollutants." Journal of Molecular Liquids 263 (August): 442-53. https://doi.org/10.1016/i.molliq.2018.05.029.

Asha, Raju C., M. A. Vishnuganth, Neelancherry Remya, N. Selvaraju, and Mathava Kumar. 2015. "Livestock Wastewater Treatment in Batch and Continuous Photocatalytic Systems: Performance and Economic Analyses." Water, Air, \& Soil Pollution: Focus $226 \quad$ (5): 132. https://doi.org/10.1007/s11270-015-2396-4.

Ashraf, Muhammad Aqeel. 2017. "Persistent Organic Pollutants (POPs): A Global Issue, a Global Challenge." Environmental Science and Pollution Research International 24 (5): 4223-27. https://doi.org/10.1007/s11356-015-5225-9.

Ashton, Melanie, and Pia M. Kohler. 2010. "Paying for POPs: Negotiating the Implementation of the Stockholm Convention in Developing Countries." International Negotiation 15 (3): 459-84. https://doi.org/10.1163/157180610X529636.

Bavuge, Mr Bernardin, Aloys Kamatali, and Abias Mbonigaba. 2020. Characterization of Persistent Organic Pollutants (POPs) and Its Adverse Effects on Environment and Public Health in Rwanda. https://doi.org/10.5281/zenodo.3633576.

Center for International Climate Research. 2015. "Second Opinion on IFC Green Bond Framework."

Committee on the Significance of International Transport of Air Pollutants, ed. 2010. "Persistent Organic Pollutants." In Global Sources of Local Pollution: An Assessment of Long-Range Transport of Key Air Pollutants to and from the United States. 500 Fifth street, N.W. Washington, DC 20001: National Academies Press. https://www.nap.edu/read/12743/chapter/7.

Eckley, Noelle. 2001. "TRAVELING TOXICS The Science, Policy, and Management of Persistent Organic Pollutants." Environment: Science and Policy for Sustainable Development 43 (7): 24-36. https://doi.org/10.1080/00139150109604496.

Inclusive Development International. 2016. "IFC Quietly Funding Coal Boom."

International Finance Corporation. n.d. "Evaluating Capital-Investment Proposals." Accessed December 29, 2020a. https://www.ncbi.nlm.nih.gov/pubmed/102429 78.

International Finance Corporation. n.d. "How to Apply for Financing." Accessed December 29, 2020b. https://www.ifc.org/wps/wcm/connect/corp ex t content/ifc external corporate site/solutions/ how-to-apply-for-financing.
International Finance Corporation. 2012. "Policy on Environmental and Social Sustainability."

International Finance Corporation. 2020. "IFC Annual Report 2020: IFC 3.0: A Strategy for Creating Markets."

International Finance Corporation. n.d. "Environmental, Health, and Safety Guidelines." Accessed January 2 , 2021c. https://www.ifc.org/wps/wcm/connect/Topics Ext Content/IFC External Corporate Site/Sustai nability-At-IFC/Policies-Standards/EHSGuidelines/.

International Finance Corporation. n.d. "IFC's Green Bonds Process." Accessed January 2, 2021d. https://www.ifc.org/wps/wcm/connect/corp ex t content/ifc external corporate site/about+ifc new/investor+relations/irproducts/ifc+green+bonds+process.

Kallenborn, Roland, Crispin Halsall, Maud Dellong, and Pernilla Carlsson. 2012. "The Influence of Climate Change on the Global Distribution and Fate Processes of Anthropogenic Persistent Organic Pollutants." Journal of Environmental Monitoring: JEM 14 (11): 2854-69. https://doi.org/10.1039/c2em30519d.

Ma, Jianmin, Hayley Hung, and Robie W. Macdonald. 2016. "The Influence of Global Climate Change on the Environmental Fate of Persistent Organic Pollutants: A Review with Emphasis on the Northern Hemisphere and the Arctic as a Receptor." Global and Planetary Change 146 (November): $\quad$ 89-108. https://doi.org/10.1016/i.gloplacha.2016.09.01 1.

Meij, Ruud, and Henk te Winkel. 2007. "The Emissions of Heavy Metals and Persistent Organic Pollutants from Modern Coal-Fired Power Stations." Atmospheric Environment 41 (40): 9262-72. https://doi.org/10.1016/i.atmosenv.2007.04.04 $\underline{2 .}$

Milic, Jelena, Marijana Curcic, Zvonko Brnjas, Hristina Carapina, Jasminka Randjelovic, Katarina Krinulovic, and Aleksandar Jovovic. 2019. "The Socio-Economic Impact Timeline in Serbia for Persistent Organic Pollutants (POPs)." The Science of the Total Environment 688 (October): 486-93. https://doi.org/10.1016/j.scitotenv.2019.06.161

Morgado, Naeeda Crishna, and Bérénice Lasfargues. 2017. "Engaging the Private Sector for Green Growth and Climate Action: An Overview of Development Co-Operation Efforts." 34. OECD Development Cooperation Working Papers. https://www.cbd.int/financial/2017docs/oecdprivate2017.pdf. 
Muller, Nicole, Johanna Saari, and Bernd Novack. 2010. "Photocatalysis for Water Treatment." ObservatoryNano.

Nguyen, Van-Huy, Siwaporn Meejoo Smith, Kitirote Wantala, and Puangrat Kajitvichyanukul. 2020. "Photocatalytic Remediation of Persistent Organic Pollutants (POPs): A Review." Arabian Journal of Chemistry 13 (11): 8309-37. https://doi.org/10.1016/j.arabjc.2020.04.028.

Noyes, Pamela D., Matthew K. McElwee, Hilary D. Miller, Bryan W. Clark, Lindsey A. Van Tiem, Kia C. Walcott, Kyle N. Erwin, and Edward D. Levin. 2009. "The Toxicology of Climate Change: Environmental Contaminants in a Warming World." Environment International 35 (6): 97186.

https://doi.org/10.1016/i.envint.2009.02.006.

Office of the Compliance Advisor Ombudsman. 2012. "CAO Audit of a Sample of IFC Investments in ThirdParty Financial Intermediaries."

Office of the Compliance Advisor Ombudsman. 2017a. “Third Monitoring Report of IFC's Response to: CAO Audit of a Sample of IFC Investments in Third-Party Financial Intermediaries."

Office of the Compliance Advisor Ombudsman. 2017b. "India / Tata Ultra Mega-01/Mundra and Anjar." November 9, 2017. http://www.caoombudsman.org/cases/case detail.aspx?id=171.

Office of the Compliance Advisor Ombudsman. 2019. "Philippines / Rizal Commercial Banking Corporation (RCBC)-01." November 19, 2019. http://www.cao-

ombudsman.org/cases/case detail.aspx?id=1266

Prüss-Ustün, Annette, Carolyn Vickers, Pascal Haefliger, and Roberto Bertollini. 2011. "Knowns and Unknowns on Burden of Disease due to Chemicals: A Systematic Review." Environmental Health: A Global Access Science Source 10 (January): $9 . \quad$ https://doi.org/10.1186/1476069X-10-9.

Rigét, Frank, Anders Bignert, Birgit Braune, Maria Dam, Rune Dietz, Marlene Evans, Norman Green, et al. 2019. "Temporal Trends of Persistent Organic Pollutants in Arctic Marine and Freshwater Biota." The Science of the Total Environment 649 (February): 99-110. https://doi.org/10.1016/i.scitotenv.2018.08.268

Sahu, S. K., R. C. Bhangare, P. Y. Ajmal, S. Sharma, G. G. Pandit, and V. D. Puranik. 2009. "Characterization and Quantification of Persistent Organic Pollutants in Fly Ash from Coal Fueled Thermal Power Stations in India." Microchemical Journal, Devoted to the Application of Microtechniques in All Branches of Science 92 (1): 92-96. https://doi.org/10.1016/j.microc.2009.02.003.

Scheringer, Martin. 2009. "Long-Range Transport of Organic Chemicals in the Environment." Environmental Toxicology and Chemistry / SETAC 28 (4): 677-90. https://doi.org/10.1897/08324R.1.

Secretariat of the Stockholm Convention. n.d. "Exemptions Overview." Accessed January 9, 2021. http://chm.pops.int/implementation/exemption s/overview/tabid/789/default.aspx.

The World Bank. n.d. "About the World Bank." Accessed January 1 , 2021. https://www.worldbank.org/en/about.

Varjani, Sunita J., Edgard Gnansounou, and Ashok Pandey. 2017. "Comprehensive Review on Toxicity of Persistent Organic Pollutants from Petroleum Refinery Waste and Their Degradation by Microorganisms." Chemosphere 188 (December): 280-91.

https://doi.org/10.1016/i.chemosphere.2017.09 .005.

Wang, Xiaoping, Dianchao Sun, and Tandong Yao. 2016. "Climate Change and Global Cycling of Persistent Organic Pollutants: A Critical Review." SCIENCE CHINA Earth Sciences 59 (10): 1899-1911. https://doi.org/10.1007/s11430-016-5073-0.

Wania, F., and D. Mackay. 1996. "Peer Reviewed: Tracking the Distribution of Persistent Organic Pollutants." Environmental Science \& Technology 30 (9): 390A - 6A. https://doi.org/10.1021/es962399q.

World Bank Group. 2017. "Lebanon Starts to Get Rid of Persistent Organic Pollutants That Endanger Environment and Health." May 12, 2017. https://www.worldbank.org/en/news/feature/ 2017/05/12/lebanon-starts-to-get-rid-ofpersistent-organic-pollutants-that-endangerenvironment-and-health.

Lok Ming Tam is a postdoctoral researcher in the Department of Biology at the University of Rochester where he studies mechanisms of aging. He holds a Ph.D. degree in Environmental Toxicology from the University of California, Riverside. In addition to scientific research, Lok Ming is interested in science policy, advocating for diversity, equity, and inclusion, as well as being part of innovative mechanisms to communicate science to general audiences. 
Wesley Chiang is a doctoral student in the Department of Biochemistry and Biophysics at the University of Rochester Medical Center, New York, USA. His thesis work focuses on developing quantum dot-based tools for investigating neurological disorders. Beyond his research, Wesley is interested in the representation of gender and sexual minorities in STEM.

Khang T. Huynh is a Ph.D. candidate in Biomedical Engineering at the University of Rochester. He is currently developing and using techniques for two-photon adaptive optics scanning light ophthalmoscopy to study function and metabolism in the living retina at a cellular scale. Equally passionate about policy and communication, he is Vice President of the University of Rochester Science Policy Initiative and a former Science Communication Training Fellow with the Association for Research in Vision and Ophthalmology. Through these channels, he advocates for environmental, healthcare, and working class issues. He received a B.S from The University of Texas at Austin and a M.S. from the University of Rochester.

\section{Acknowledgements}

The authors are grateful for the assistance of Dr. Holly Mayton and William Ota in navigating the topic of this manuscript.

\section{Disclaimer}

The authors' views do not necessarily reflect those of their respective departments or sponsors. 